Article

\title{
Low Velocity Impact and Compression after Impact Properties on Gamma Irradiated Kevlar/Oil Palm Empty Fruit Bunch Hybrid Composites
}

\author{
Siti Madiha Muhammad Amir ${ }^{1,2}$, Mohamed Thariq Hameed Sultan 1,3,4,*,

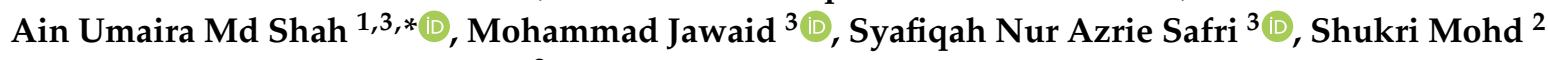 \\ and Khairul Anuar Mohd Salleh ${ }^{2}$ \\ 1 Department of Aerospace Engineering, Faculty of Engineering, Universiti Putra Malaysia, \\ Serdang 43400, Selangor Darul Ehsan, Malaysia; madiha_amir@nm.gov.my \\ 2 Industrial Technology Division, Malaysian Nuclear Agency, Bangi 43000, Selangor, Malaysia; \\ shukri_mohd@nm.gov.my (S.M.); khairul_anuar@nm.gov.my (K.A.M.S.) \\ 3 Laboratory of Biocomposite Technology, Institute of Tropical Forestry and Forest Products (INTROP), \\ Universiti Putra Malaysia, Serdang 43400, Selangor, Malaysia; jawaid@upm.edu.my (M.J.); \\ snasafri@gmail.com (S.N.A.S.) \\ 4 Aerospace Malaysia Innovation Centre (944751-A), Prime Minister's Department, MIGHT Partnership Hub, \\ Jalan Impact, Cyberjaya 63000, Selangor Darul Ehsan, Malaysia \\ * Correspondence: thariq@upm.edu.my (M.T.H.S.); ainumaira91@gmail.com (A.U.M.S.)
}

Received: 30 April 2020; Accepted: 10 June 2020; Published: 3 July 2020

\begin{abstract}
This work investigates the dynamic impact response of Kevlar/oil palm empty fruit bunch (EFB) hybrid composite structures with/without gamma radiation under low velocity impact (LVI) and compression after impact (CAI) test. The layering pattern Kevlar/oil palm EFB/Kevlar (K/OP/K) was applied in this work. Irradiation with gamma ray with various doses were applied from 25-150 kGy. LVI results shows that hybrid Kevlar/oil palm EFBs (Kevlar/OPEFB) that were not irradiated have greater impact resistance as compared to irradiated hybrid Kevlar/OPEFB. It was also observed that the hybridization of Kevlar/OPEFB with gamma irradiation helped to improve the compressive residual strength of the composites. It was found that Kevlar/OPEFB hybrid composites with the layering sequence $\mathrm{K} / \mathrm{OP} / \mathrm{K}$ can withstand up to $35 \mathrm{~J}$ of impact energy, with the optimum gamma radiation dose at $50 \mathrm{kGy}$.
\end{abstract}

Keywords: oil palm; aramid fiber; hybrid; laminates; impact behavior; residual stress

\section{Introduction}

There are various applications that have been using hybrid composites as the main component in the system, for example aircraft and cars [1]. Hybrid composites are divided into several categories, those combining the natural and synthetic materials, natural/natural composites, synthetic/synthetic composites, and natural/synthetic composites. Currently, there has been a demand for replacing or minimizing the use of synthetic fiber with natural fiber either by hybridizing the reinforcements with natural-natural fiber or natural-synthetic fibers. Natural fibers that are commonly used in hybrid composites are jute, oil palm empty fruit bunch (EFB), kenaf, and sugar palm, etc.

Composite strength can be enhanced using several methods, such as hybridization and fiber surface treatment. Further, radiation on the materials can also affect the composite strength. Exposure to ionizing radiation through using Electron Beam Machine (EBM) and gamma radiation is one of the alternatives to enhance the properties of the composites. Exposure to gamma radiation offers several 
benefits, such as continuous operation, less atmospheric pollution and minimal time required for the treatment [2].

In developing new composite materials, the characterization of the materials is important. The characterizations are usually undertaken by conducting physical and mechanical tests, such as the tensile, flexural and compression tests. However, hybrid composites can also be characterized using impact studies. There are few tests related to the impact tests, which are the Izod and Charpy tests. However, in this work, focus is given to the low velocity impact (LVI) test, sometimes known as the drop weight test [3].

Matrix-fiber cracking, fiber breaking, delamination and perforation are the most common damages experience from the LVI test $[4,5]$. It is crucial to identify the mode of failure during an LVI event. Identifying the mode of failure will provide information about the impact and the composite's residual strength.

A previous study was undertaken on the impact properties of hybrid composites made from oil palm EFB (OPEFB) and modified unplasticized poly (vinyl chloride) using Izod impact testing [6]. It was found that the impact strength of the composites was affected by the PVC-U. Sivakumar et al. [7] studied the LVI response of short OPEFB fiber-reinforced metal laminates. The composites were fabricated based on the various weight percentages of OPEFB fiber. Charpy tests on the flatwise and edgewise of the composites were conducted during this work. It was found that the flatwise impact properties displayed better impact resistance compared to the edgewise impact properties.

Channabasavaraju et al. [8] did not managed to justify the LVI damage on the Kevlar composites because further examination was needed to examine the damages. Therefore, suitable methods need to be used to examine the impact damage on the Kevlar composites.

There have been various studies on the LVI damage on hybrid composites. The purpose of conducting impact studies is to evaluate the effect of hybrid structures on the response of LVI [9]. Ying et al. [9] investigated the LVI response on carbon-aramid/epoxy hybrid composites. It was found that the damage area on aramid fabric when aramid fabric acts as the impact surface were bigger compared to others. Gustin et al. [10] studied the LVI response of a combination of Kevlar/carbon fiber sandwich composites and found that the composite performance increased when the Kevlar fiber acted at the outer surface of the composites. The Kevlar composites had improved significantly by absorbing the maximum energy.

Other researchers have also investigated the impact resistance of hybrid composites made from glass fibers and Kevlar fibers. The authors of [11] concluded that the addition of Kevlar fiber to glass fiber improved the composite capability of the carrying load, energy absorbed and damage area. The results proved that Kevlar has better resistance towards impact loading due to the ability of Kevlar fiber to absorb more energy. It was found that the damage pattern of Kevlar fiber has a smaller damage area compared to glass fiber. There is also other research on hybrid aramid-glass fiber/epoxy composites [12]. However, in this work the LVI behavior was studied on water immersion ageing woven aramid-glass fiber/epoxy composites. From this research, the author concluded that the water absorption did not affect the absorbed energy. Ismail et al. [13] studied the LVI response of hybrid kenaf-Kevlar composite laminates. From their studies, the authors concluded that the different types of fiber combination exhibited different results in the LVI event. The factor of thickness influenced the impact dynamics of the hybrid composites.

Compression after impact (CAI) testing is important, especially in evaluating new materials. Several research projects have been conducted using CAI test. Aktas et al. [5] studied the behavior of CAI on laminated composite plates due to LVI at high temperature. The tests were conducted on composites made of glass/epoxy composites. From the results, it can be concluded that the impact testing temperature and impact energy affect the composite CAI strength. It was found that at an impact testing temperature of $100{ }^{\circ} \mathrm{C}$ the composite CAI strength reduced drastically, while at a $20^{\circ} \mathrm{C}$ impact temperature, the CAI strength of the composite experienced minimum reduction. Martin et al. [14] analyzed the CAI behavior of tufted carbon/epoxy laminated composites. It was 
found that the damage area was reduced for composites made from tufting reinforcement when compared to non-tufted laminates.

A study on CAI has been performed on hybrid composites consisting of Kevlar/carbon fiber [10]. In this work, the reduction in compressive strength when replacing the carbon fiber layers with the Kevlar or hybrid layers was determined. As well as studies of CAI on synthetic fiber, Rubio-Lopez et al. [3] conducted research on biodegradable composites made from flax/PLA.

Previous studies show that there are limited studies on the impact damage properties on Kevlar/OPEFB hybrid composite using LVI and CAI testing. Further, very few studies focus on the effect of radiation dose on the impact performance of hybrid composites. Natural fiber hybrid composite has the potential to be used in medical applications, transportation and the military industry; therefore, in this research, the effect of the gamma radiation on the LVI and CAI response of the Kevlar/OPEFB hybrid composites was investigated.

\section{Materials and Methods}

Kevlar fibers woven mat orientated in $0 / 90^{\circ}$ with a thickness of $1 \mathrm{~mm}$ were supplied by ZKK Sdn. Bhd (Selangor, Malaysia). The OPEFB mat with random orientation and a thickness of $7 \mathrm{~mm}$ were supplied by HK Kitaran Sdn. Bhd, Pulau Pinang, Malaysia. The epoxy resin/hardener used were Zeepoxy HL002TA and Zeepoxy HL002TB which also provided by ZKK Sdn. Bhd. The mixing ratio between the epoxy resin and the hardener was 2:1. The properties of the OPEFB and Kevlar fiber are shown in Table 1.

In fabricating the samples, the hand lay-up technique was used. A mold made of carbon steel with dimension $300 \mathrm{~mm} \times 200 \mathrm{~mm}$ was used, as shown in Figure 1. The mold was covered with glazing wax as the release agent.

Table 1. Physical and mechanical properties of Kevlar and oil palm empty fruit bunch (OPEFB) fiber.

\begin{tabular}{ccccc}
\hline Properties & Density $\left(\mathrm{g} / \mathrm{cm}^{\mathbf{3}}\right)$ & $\begin{array}{c}\text { Young's Modulus } \\
\mathbf{( G P a )}\end{array}$ & $\begin{array}{c}\text { Elongation at Break } \\
\mathbf{( \% )}\end{array}$ & Reference \\
\hline Kevlar & 1.44 & 70 & 3.6 & {$[15]$} \\
OPEFB & $0.7-1.55$ & $1-9$ & $8-18$ & {$[16]$} \\
\hline
\end{tabular}

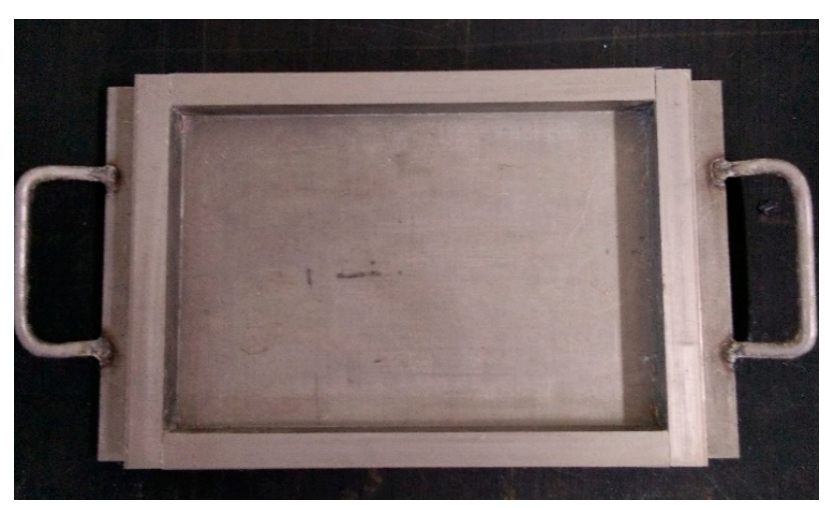

Figure 1. Carbon steel mold.

The hybrid composite comprised of the OPEFB fiber mat and woven Kevlar fiber was layered together. The layer of OPEFB fiber was sandwiched in between the layer of Kevlar fiber $(\mathrm{K} / \mathrm{OP} / \mathrm{K})$ - the layering pattern of the hybrid composite pattern is shown in Figure 2. After the fabrication process, the mold was closed to remove the access to resin and left at room temperature for $24 \mathrm{~h}$ for the curing process. Later, the mold was removed from the compress machine and left at room temperature for $24 \mathrm{~h}$ for the curing process. After the curing process, the composites were then post-cured in the oven with temperature of $80^{\circ} \mathrm{C}$ for $3 \mathrm{~h}$. 


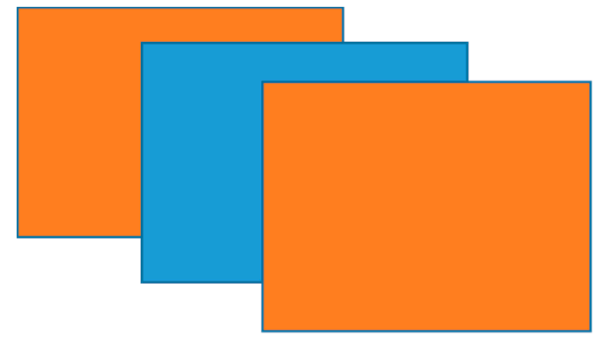

\section{Oil Palm EFB}

Figure 2. The layering pattern of the hybrid composites.

After drying, the hybrid composites were cut into dimensions of $100 \mathrm{~mm} \times 150 \mathrm{~mm}$ before they underwent the gamma irradiation process at 25,50 and $150 \mathrm{kGy}$. The thickness of the hybrid composites tested were $7 \mathrm{~mm} \pm 0.5 \mathrm{~mm}$. The size of samples for both the LVI test and the CAI test were $100 \mathrm{~mm}$ $\times 150 \mathrm{~mm}$ with $7 \mathrm{~mm}$ thickness. The irradiation machine model used was JS 10000 IR219 (Nordion, Kajang, Malaysia). For the irradiation process, the Cobalt- 60 radioactive material was used to irradiate the hybrid composites. The exposure time depended on the machine activity source.

In this work, LVI tests were conducted using a drop weight impact tester model IMATEK IM10 (IMATEK, Serdang, Malaysia), with IMATEK software used to process the results. A striker with a weight of $5.101 \mathrm{~kg}$ was dropped from chosen heights with gravitational acceleration of $9.82 \mathrm{~ms}^{-2}$. Table 2 shows the impact height and impact energy for each sample. A total of 84 samples were tested, where 3 repetitions were conducted for every joule (10-40 J) with different heights $(0.2-0.8 \mathrm{~m})$ of specific radiation dose (0-150 kGy).

The CAI tests were then conducted to determine the post-impact properties, especially the residual compressive strength of the impacted hybrid composites. The tests were performed according to ASTM D7137 [17] using an anti-buckling Boeing CAI fixture. Figure 3 shows the $300 \mathrm{kN}$ load cell universal testing machine, model Shimadzu AGX (Shimadzu, Kuala Lumpur, Malaysia), used in the test. A compressive load at a displacement rate of $1.25 \mathrm{~mm} / \mathrm{min}$ was applied until the samples failed.

Table 2. Experimental design for low velocity impact (LVI) testing.

\begin{tabular}{cccc}
\hline Radiation Dose (kGy) & Energy Level (J) & Impact Velocity $\left(\mathbf{m s}^{\mathbf{- 1}}\right)$ & Height (m) \\
\hline & 10 & 1.98 & 0.2 \\
& 15 & 2.43 & 0.3 \\
$0,25,50,150$ & 20 & 2.80 & 0.4 \\
& 25 & 3.13 & 0.5 \\
& 30 & 3.43 & 0.6 \\
& 35 & 3.71 & 0.7 \\
& 40 & 3.96 & 0.8 \\
\hline
\end{tabular}

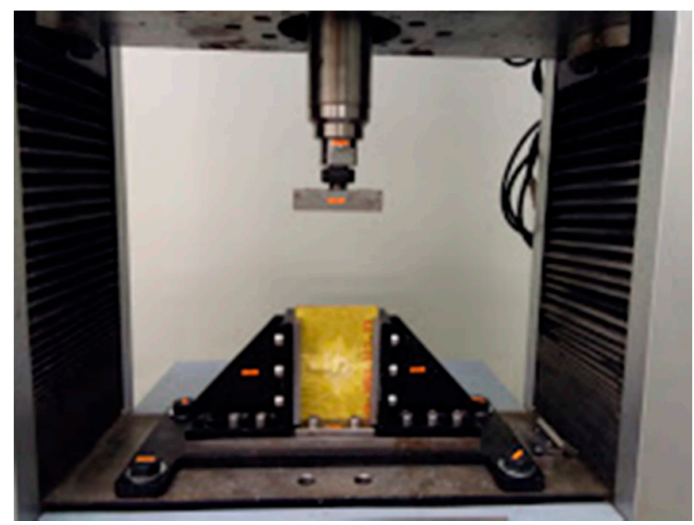

Figure 3. Shimadzu AGX ultimate testing machine. 


\section{Results and Discussion}

Force-displacement analysis was conducted to obtain information on the damage progression on the samples. The diagrams obtained represented the typical behavior of the damage impact for laminated specimens and agree with Reis et al. [18]. From the graph, the closed curve indicates that the striker did not penetrate the specimen during testing. However, an open curve shows that the striker had penetrated the specimen. The maximum impact energy is shown at the highest tip of the curve while the end of the curve shows the absorbed energy [13]. The maximum displacement is achieved when there is the bounce phenomenon between the striker and the samples. During this event, the sample transfer the excess impact energy back to the striker elastically [13]. Figure 4a-d show the force-displacement at $10 \mathrm{~J}$ until $25 \mathrm{~J}$ for various samples with different radiation doses. At 10 , 15, 20 and $25 \mathrm{~J}$ from Figure $4 \mathrm{a}-\mathrm{d}$ the force-displacement curve were still closed, which indicates no full penetration damage in the sample. The specimens that were irradiated and not irradiated showed the same trend. This implies that the specimens being irradiated and not being irradiated are able to withstand at force 10, 15, 20 and $25 \mathrm{~J}$.

Figure 5a-c represent the force-displacement curve at energies of 30, 35 and $40 \mathrm{~J}$, respectively. The curve remained closed, which indicated no full penetration damage in the sample at energy 30 and $35 \mathrm{~J}$ for both the irradiated and non-irradiated specimens. The closed curve implies that the incident energy was fully transferred to the specimens after maximum displacement was achieved [13]. From the results, it was found that the impact resistance for all specimens, including the non-irradiated and irradiated specimens, were up to $35 \mathrm{~J}$ of impact energy. This shows that the hybrid between Kevlar/OPEFB has a better impact resistance when only Kevlar/epoxy was used [18]. The hybrid composites Kevlar/OPEFB also have higher impact resistance compared to the hybrid composites kenaf/Kevlar. The laminates of kenaf/Kevlar withstand an impact energy below $30 \mathrm{~J}$ [13].

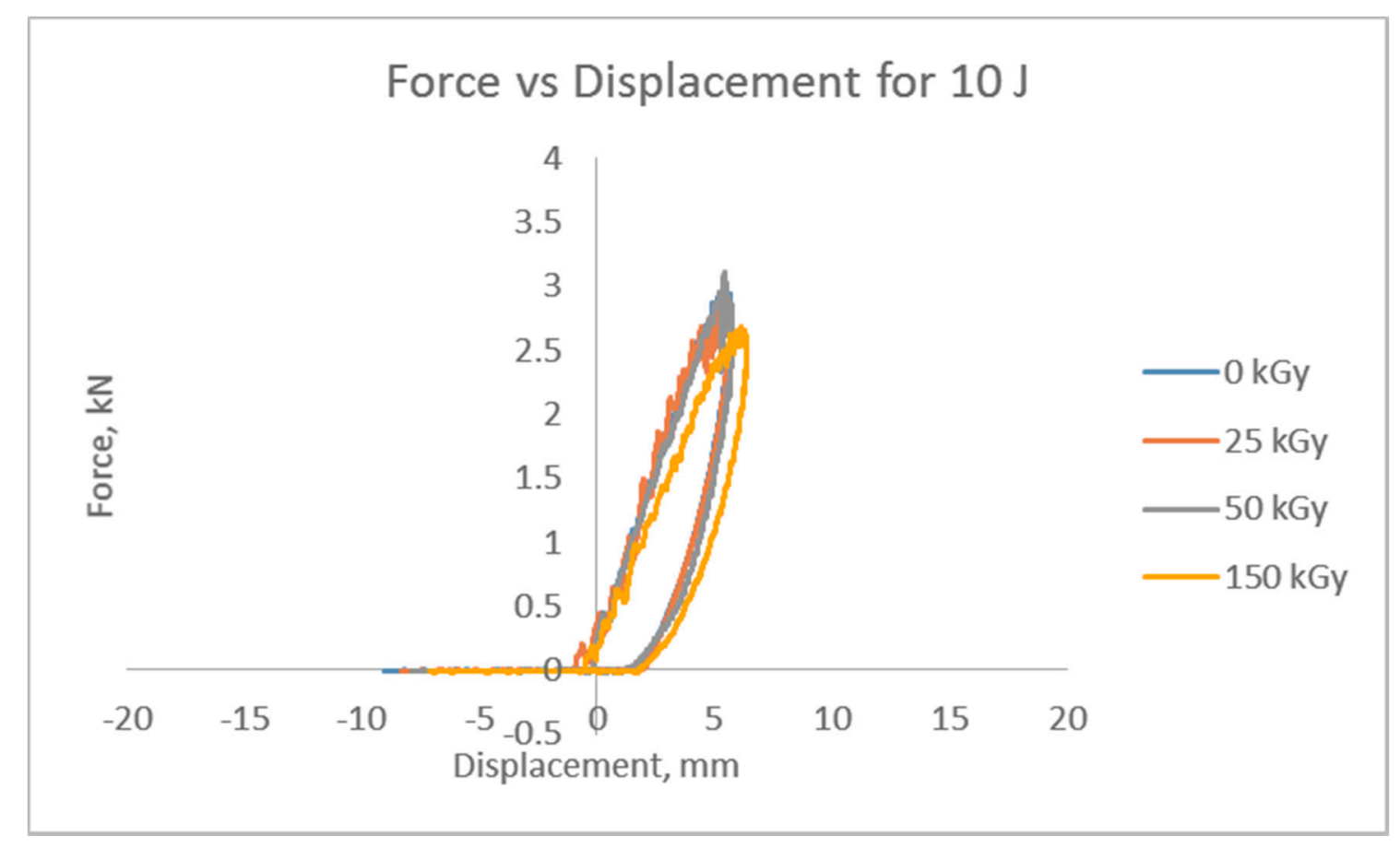

(a)

Figure 4. Cont. 


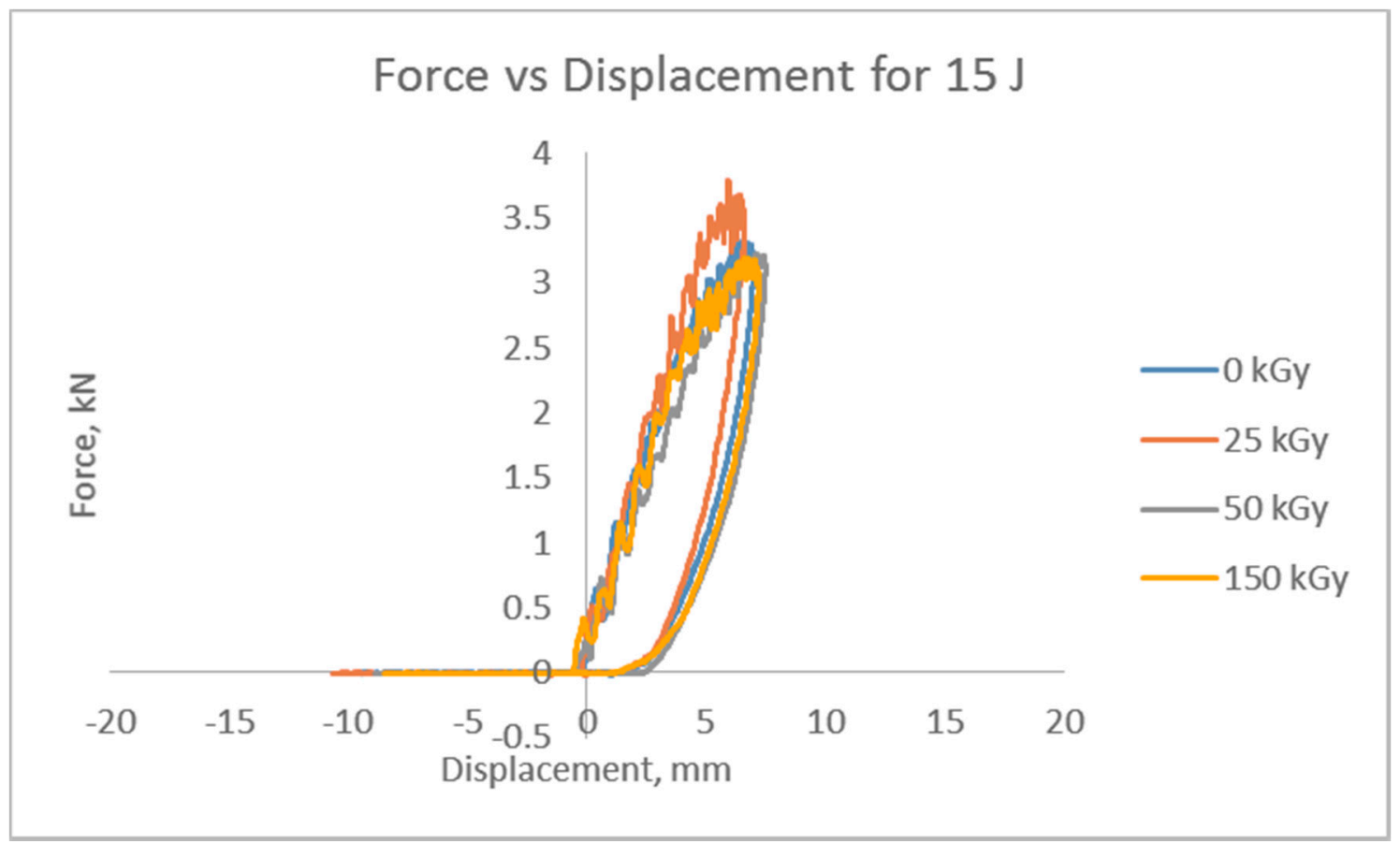

(b)

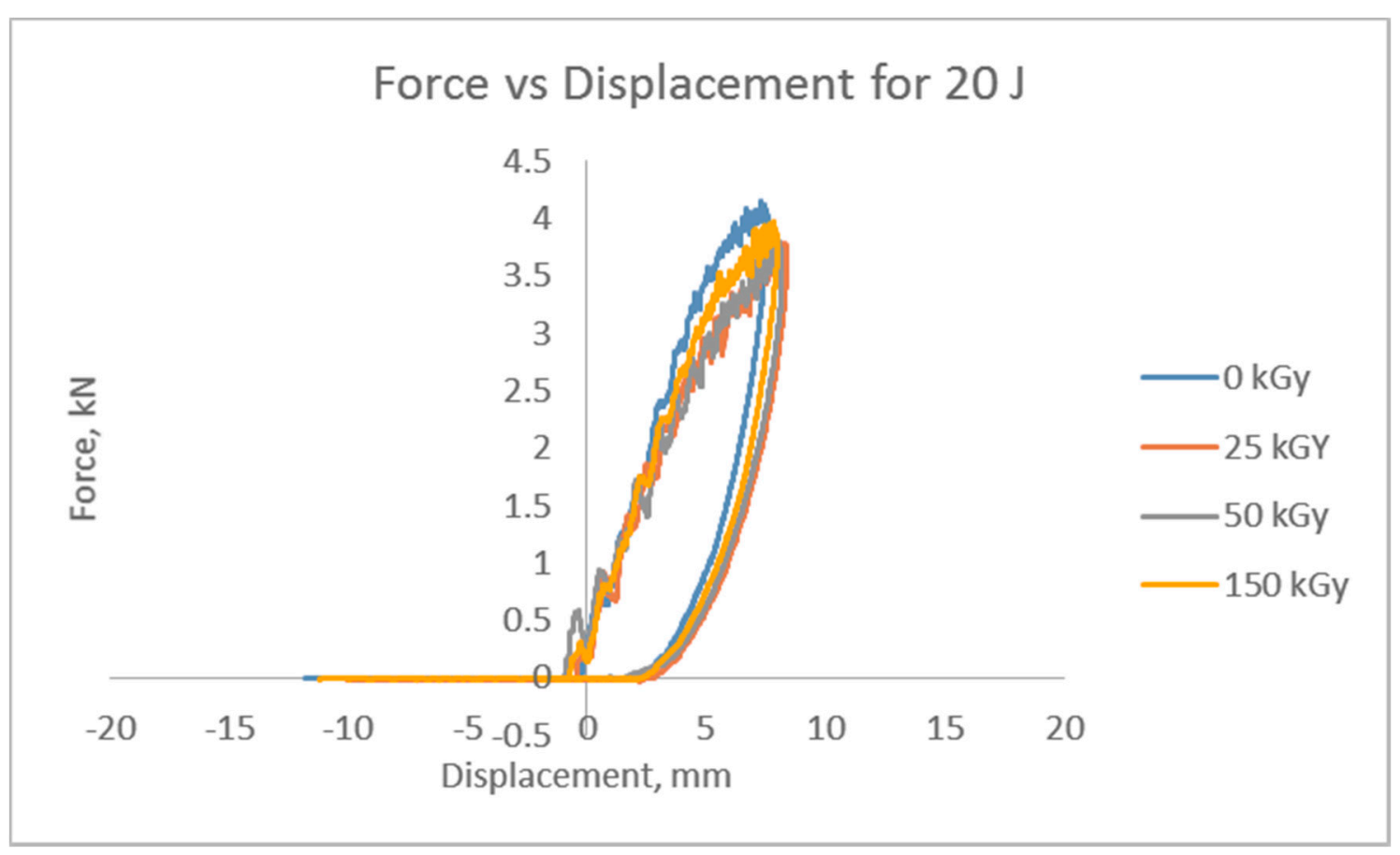

(c)

Figure 4. Cont. 


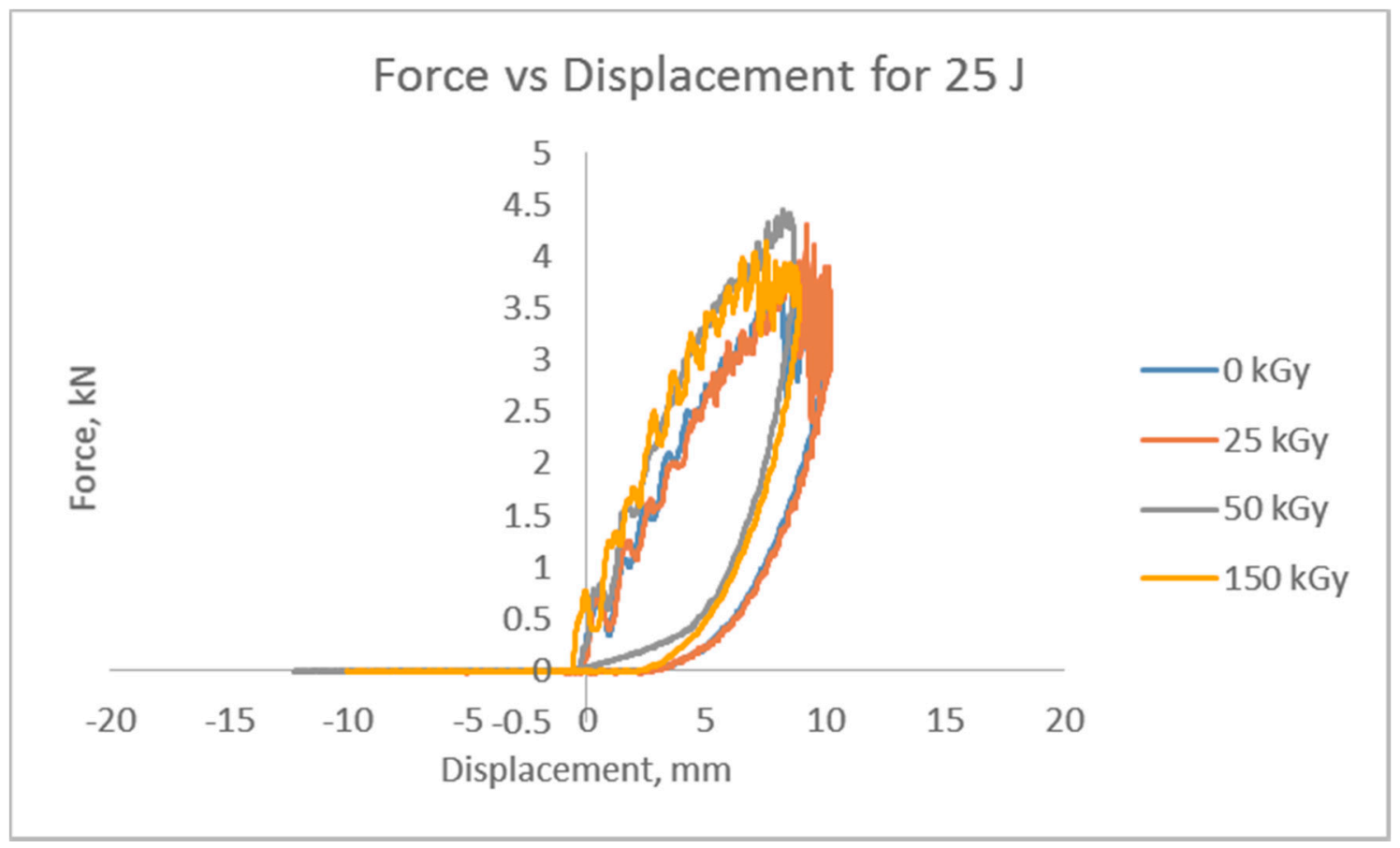

(d)

Figure 4. Force-displacement graphs for energy at (a) $10 \mathrm{~J}$, (b) $15 \mathrm{~J}$, (c) $20 \mathrm{~J}$ and (d) $25 \mathrm{~J}$.

The open curves show that the specimens that were irradiated with gamma radiation became fully penetrated at energy $40 \mathrm{~J}$, as shown in Figure $5 \mathrm{c}$. The open curve shows that, after the maximum displacement, the incident energy did not fully transfer to the specimens. The specimens transferred the impact energy back to the impactor elastically after it reached maximum displacement [13]. This result implies that at $40 \mathrm{~J}$ the energy applied exceeded the maximum allowable energy to the specimens. The results agreed with the hybrid kenaf/Kevlar, where the hybrid composites failed as impact energy approached $40 \mathrm{~J}$ [13]. However, the samples that were not irradiated still showed a closed curve, which indicated that the samples at $0 \mathrm{kGy}$ were not fully penetrated even at an energy level of $40 \mathrm{~J}$. This implies that the hybrid Kevlar/OPEFB samples that were not irradiated had a higher impact resistance compared to irradiated hybrid Kevlar/OPEFB.

In previous studies there has been evidence that gamma irradiation to the materials enhances the mechanical properties due to the improved fiber-matrix adhesion. However, in the impact event in this study, the results obtained show that the hybrid composites that were exposed to gamma radiation have lower impact resistance compared to the hybrid composites without exposure to gamma radiation. It was reported by Yahaya et al. [19] that poor fiber-matrix adhesion absorbs more energy under impact loading due to delamination and debonding damage. The result of crosslinking will produce brittle resin [20]. This implies that irradiated hybrid composites have lower impact resistance compared to non-irradiated hybrid composites.

The peak force is the maximum recorded force in an event [21]. The force increases up to a peak value, $F_{\max }$, and is followed by a drop after the peak load [18]. The peak force represents the value that the composite laminate is able to withstand under a particular impact level before experiencing major damage [18]. As the impact energy increases, the peak force also increases, and this agrees with the theory that peak force is directly related to the impact energy $[18,21]$. The results obtained obey the peak force theory, as shown in Figure 6, and the results in this work show the similar tendencies with work of Reis et al. [18]. 


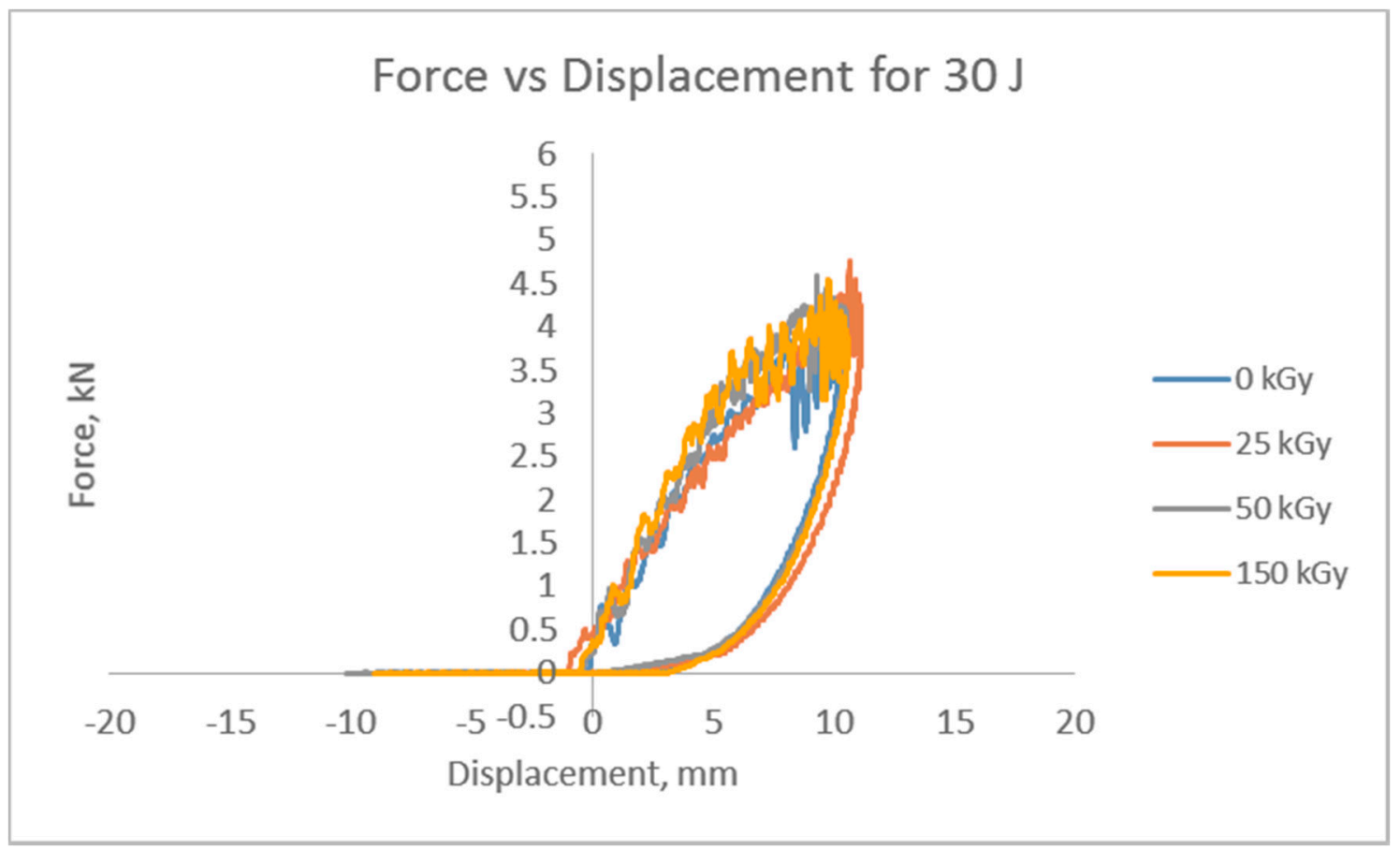

(a)

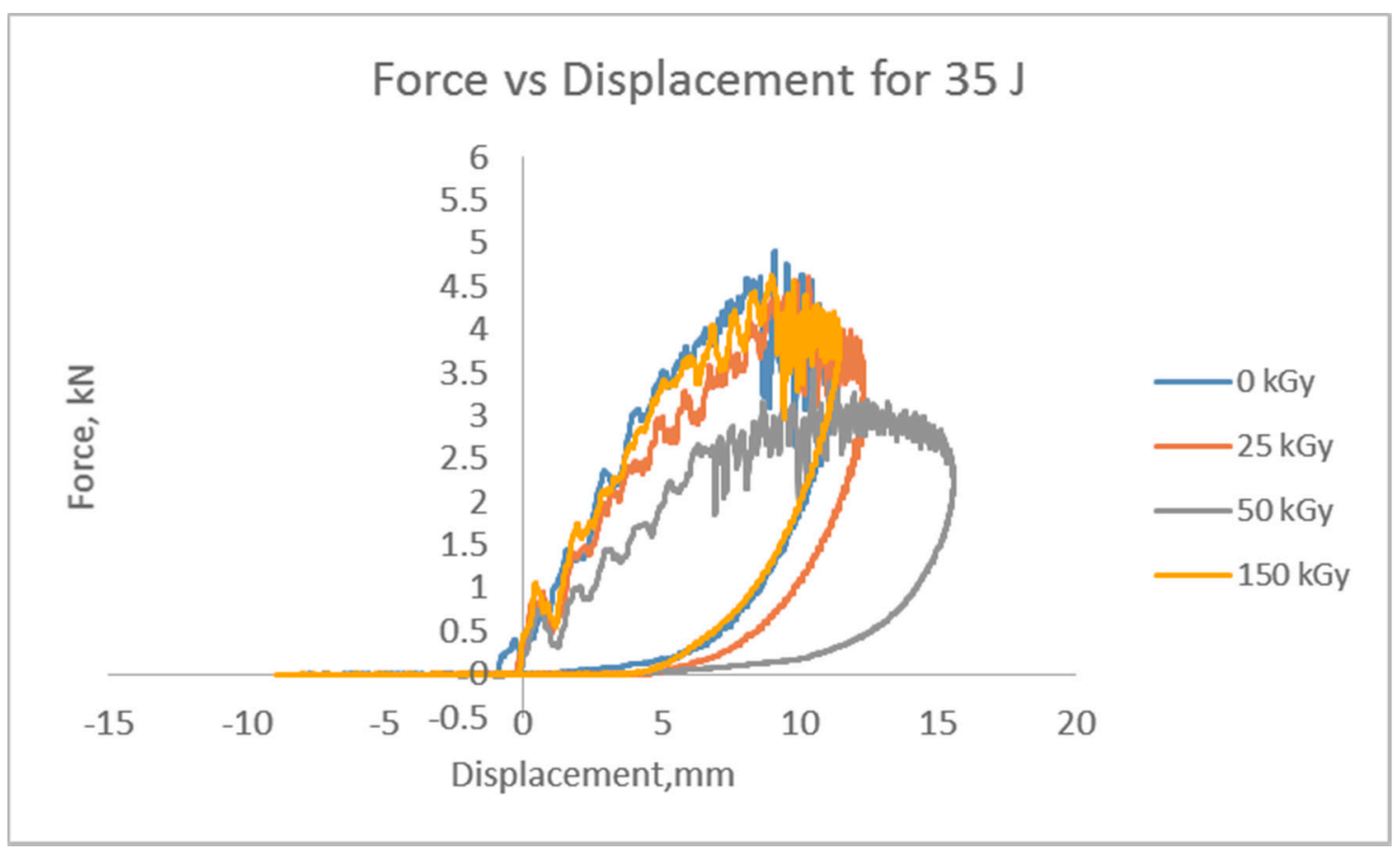

(b)

Figure 5. Cont. 


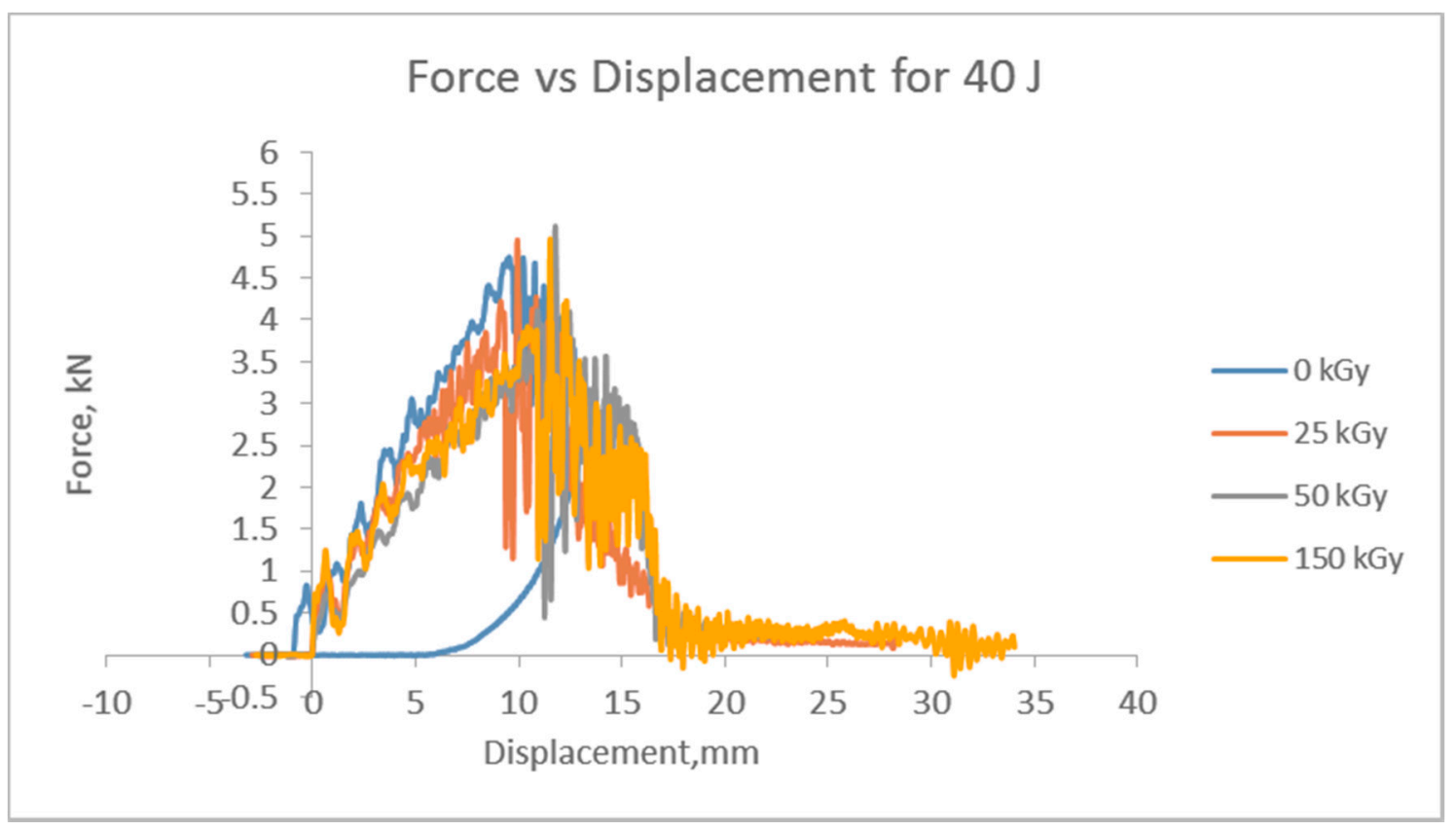

(c)

Figure 5. Force-displacement graphs for energy at (a) $30 \mathrm{~J}$, (b) $35 \mathrm{~J}$ and (c) $40 \mathrm{~J}$.

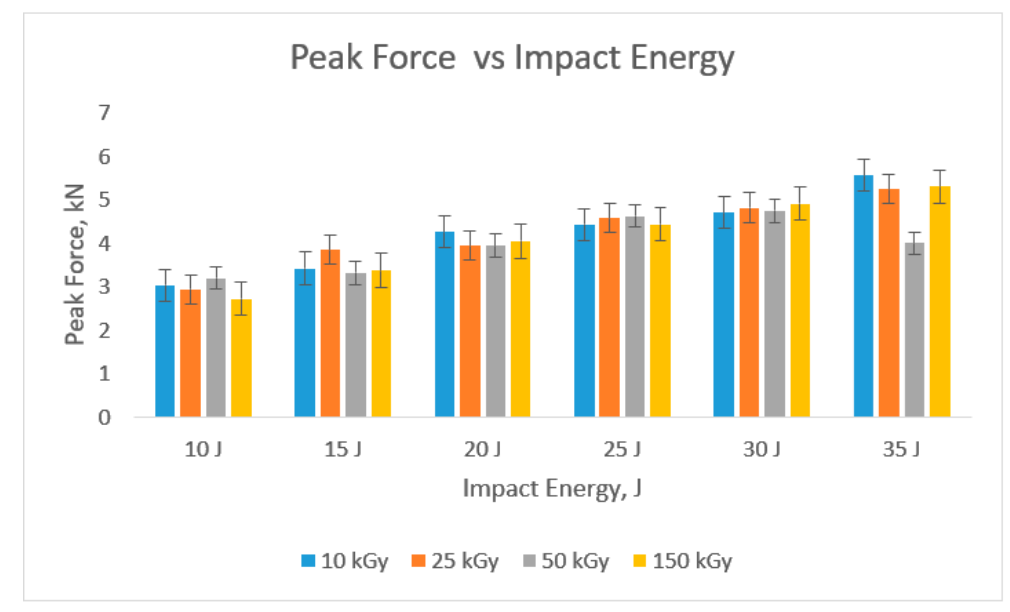

Figure 6. Peak force variation with impact energy and radiation dose.

The specimens that were not radiated, which is $0 \mathrm{kGy}$, have a higher peak force, $5.99 \mathrm{kN}$, compared to the specimens that were irradiated, as shown in Figure 6. Since the peak force is directly related to the impact energy, hence specimens that were irradiated with different radiation doses also experienced an increase in peak force when the impact energy increased. The specimens that were irradiated have a lower peak force compared to specimens that were not irradiated. In this work, the specimen damage occurs at an impact energy of $40 \mathrm{~J}$ for irradiated specimens, while specimens without radiation were still not fully penetrating at $40 \mathrm{~J}$. However, work done by Reis et al. [18] shows that the major damage occurred at $21 \mathrm{~J}$ for Kevlar/epoxy laminates. This shows that hybridizing between Kevlar/OPEFB increased the strength of the materials.

From the impact damage results, the hybrid composites without radiation with a weak fiber-matrix interface have better impact resistance compared to the irradiated hybrid composites. This agrees with Yahaya et al. [19] that the impact performance is improved in composites with weak fiber-matrix interfaces. Since epoxy is a brittle matrix, it shows lower damage resistance [22]. Unnikrishnan and 
Thachil [23] stated that cured epoxies are brittle and have poor resistance to crack initiation and growth, suggesting that irradiation epoxies have lower impact resistance compared to epoxies without radiation due to oven curing during the fabricating process as well as due to the crosslinking phenomena.

The results in Figure 7, show that as the impact energy increased, the absorbed energy increased. When absorbed energy is not equal to impact energy, the penetration threshold is not yet achieved [18]. Since the penetration threshold was not achieved, major damage did not occur in the specimens, and this shows the similar trend to this work [18]. However, this only applied at an impact energy of $35 \mathrm{~J}$. At an impact energy $40 \mathrm{~J}$, the absorbed energy for the irradiated specimens was closed to the value of the impact energy. This implies that the penetration threshold had been achieved. Hence, the full penetration occurred in the irradiated specimens at an impact energy of $40 \mathrm{~J}$. However, for non-irradiated specimens, the absorbed energy is much lesser compared to irradiated specimens. This indicated that at $40 \mathrm{~J}$, the non-irradiated specimens were not fully penetrated. These results show that the impact resistance was at an energy level of $35 \mathrm{~J}$ for irradiated specimens, but the impact resistance for non-irradiated specimens was $40 \mathrm{~J}$.

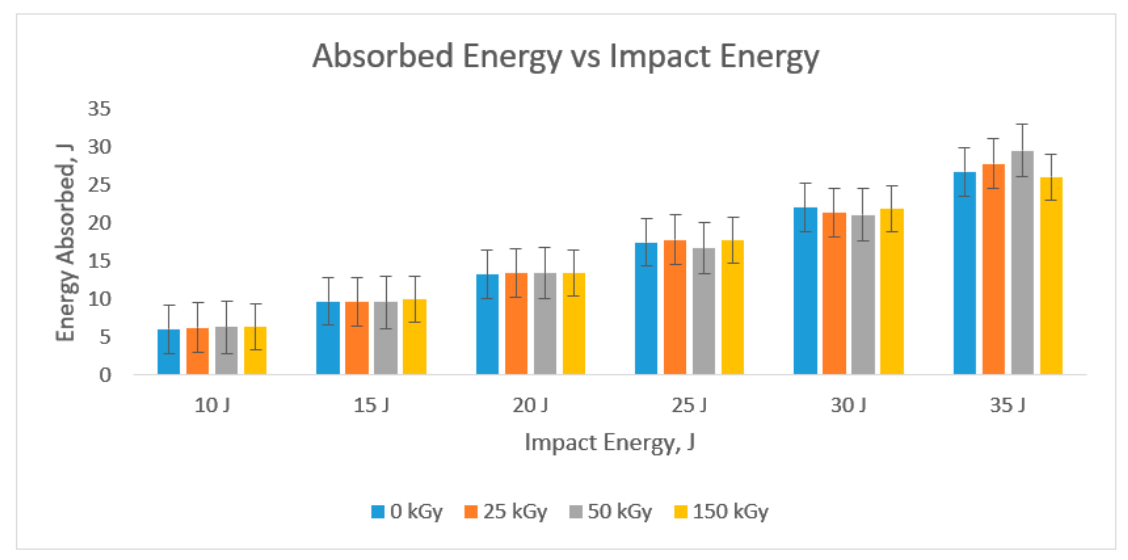

Figure 7. Energy absorbed versus impact energy.

The differences in the absorbed energy and peak force for all the tested samples were analyzed using the one-way ANOVA, as shown in Tables 3 and 4. The variance of the absorbed energy and peak force has been decomposed between the groups (BG) and within the groups (WG). The ratio between the mean square of BG and the mean square of WG is known as the $f$-value. The null hypothesis is rejected since the $p$-value of the $f$-test was less than 0.05 . From the results, the confidence level is $95 \%$ where it shows that there is a statistically significant difference in peak force and absorbed energy. The normal probability plot of absorbed energy and peak force are shown in Figures 8 and 9 . The fitness of the model has been validated since the normalization line is closer to the data points.

Table 3. ANOVA results of absorbed energy.

\begin{tabular}{cccccc}
\hline Source & DF & SS & MS & $f$-Value & $p$-Value \\
\hline Between the group (BG) & 23 & 3746.71 & 162.900 & 178.75 & 0.000 \\
Within the group (WG) & 48 & 43.74 & 0.911 & NA & NA \\
\hline
\end{tabular}

$\mathrm{DF}$, degrees of freedom; SS, sum of square; MS, mean square.

Table 4. ANOVA results of peak force.

\begin{tabular}{cccccc}
\hline Source & DF & SS & MS & $f$-Value & $p$-Value \\
\hline Between the group (BG) & 23 & 43.567 & 1.8942 & 14.18 & 0.000 \\
Within group (WG) & 48 & 6.411 & 0.1336 & NA & NA \\
\hline
\end{tabular}

$\mathrm{DF}$, degrees of freedom; SS, sum of square; MS, mean square. 


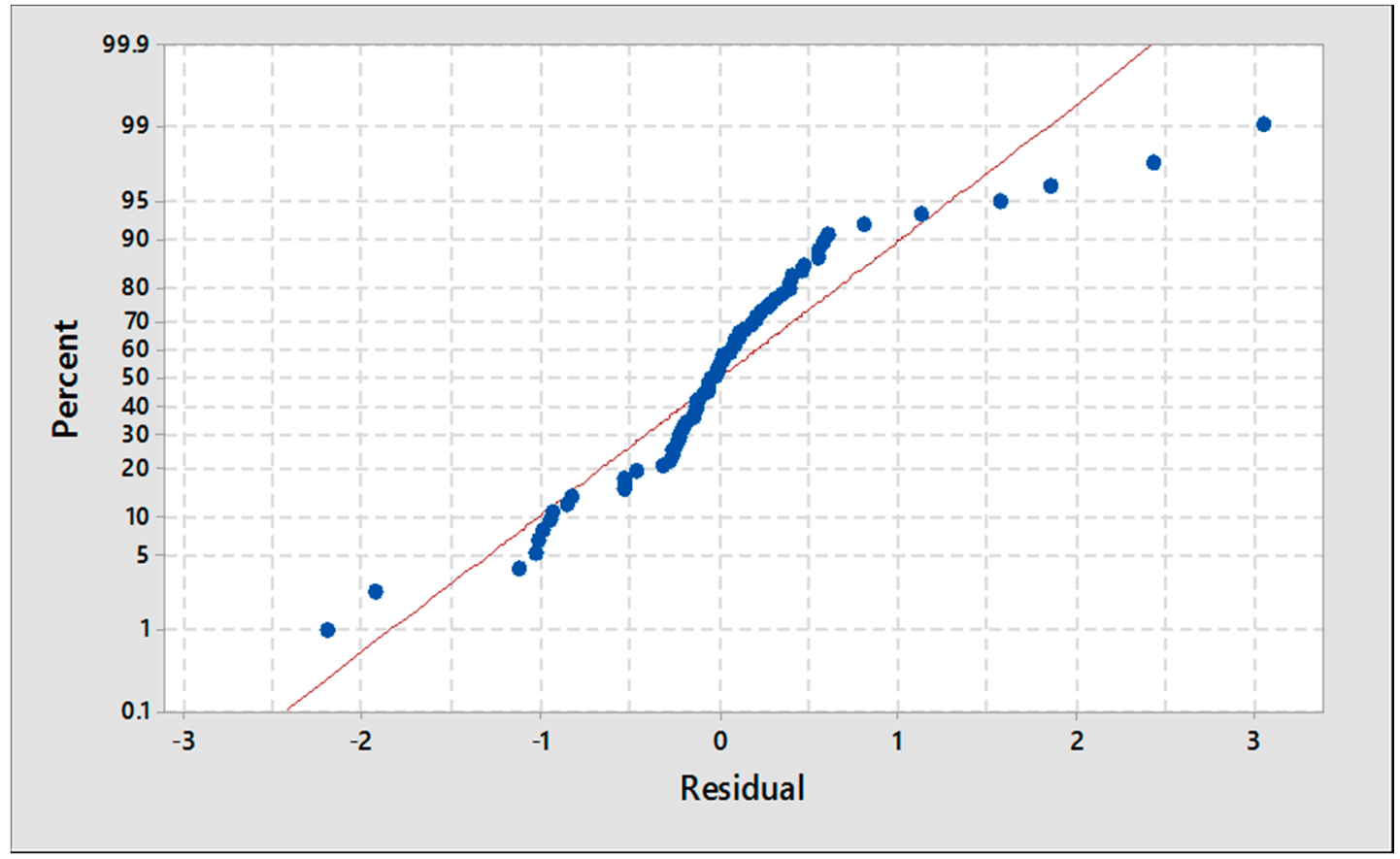

Figure 8. Normal probability plot of absorbed energy.

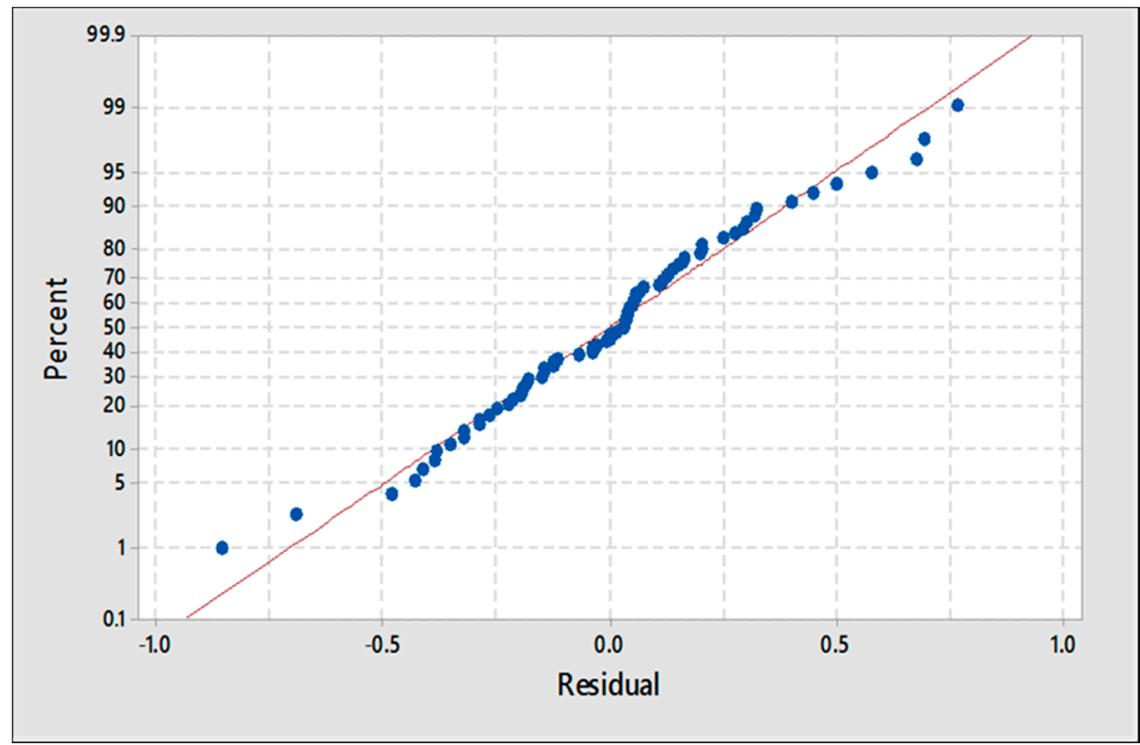

Figure 9. Normal probability plot of peak force.

The residual strengths of the impacted hybrid composites were obtained using the CAI test. From Figure 10, in general, samples with radiation have higher compressive residual strength in radiation dose $50 \mathrm{kGy}$ compared to samples without any radiation. This may be due to the crosslinking when radiation interacts with the material. In general, it is observed that as the impact energy increased the compressive residual strength decreased, especially for the non-irradiated samples and irradiated samples at $25 \mathrm{kGy}$ and $50 \mathrm{kGy}$. From the analysis, it was also observed that the combination effect of hybrid Kevlar/OPEFB with gamma radiation improved the compressive strength in hybrid samples irradiated with 50 kGy. 


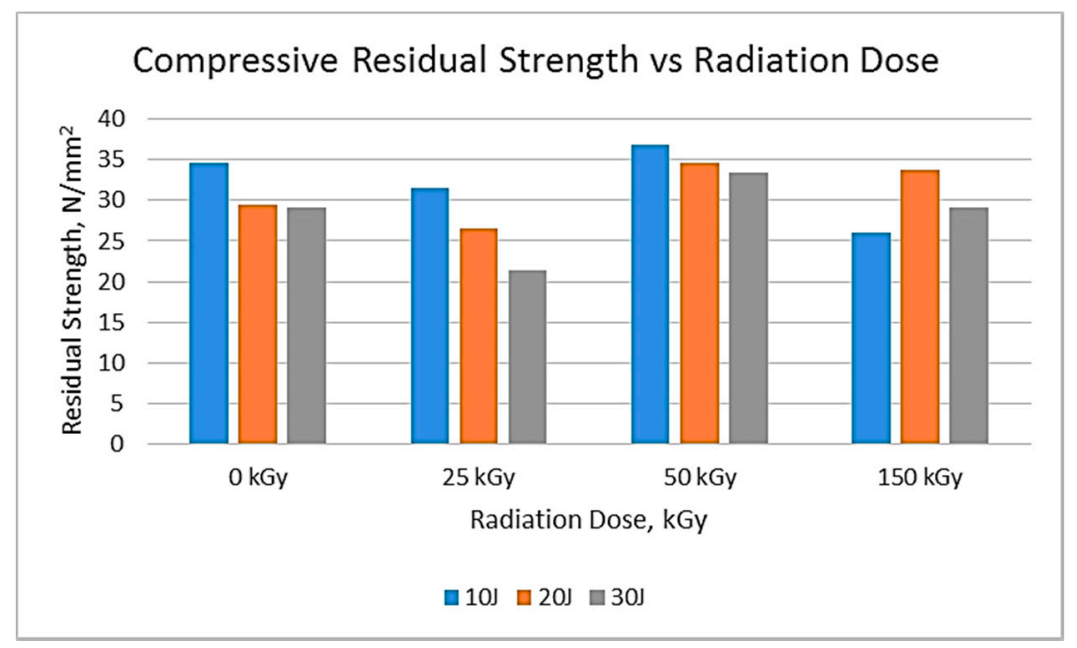

Figure 10. Compressive residual strength of the hybrid composites.

Figure 11 displays the different failure modes of the hybrid samples that underwent CAI testing subject to different energy levels. The samples failed through a combination of compression on the impacted surface and buckling on the rear surface. It led to delamination, which is perpendicular to the loading directions. Moreover, the fiber fracture and matrix cracking propagate in the area where the stress concentration is greater, leading to complete failure.

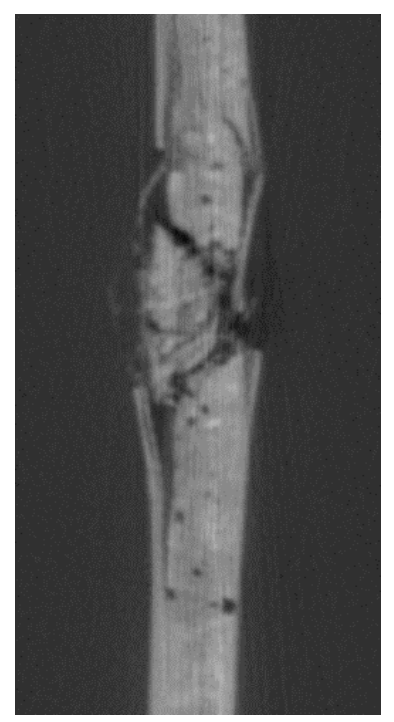

Figure 11. Computed tomography image of failure modes after the compression after impact (CAI) test at samples with an impacted energy of $35 \mathrm{~J}$.

At the back of the impacted surface, photographic images were captured using normal camera with $0 \times$ magnification; these are shown in Figure 12. Figure 12 shows the back of the impacted surface for hybrid samples that have been impacted with impact energy at 10, 20 and $35 \mathrm{~J}$.

Figure 12a shows the damage after the CAI at $10 \mathrm{~J}$. The damage observed was similar to the damage at an impact energy of $20 \mathrm{~J}$. The fiber crack damage was intensely focused at the center of the back of the impacted surface and propagated outwards from the center of the impacted surface. Unlike hybrid composites that were impacted at $20 \mathrm{~J}$, the fiber crack was observed at the center at which the area was impacted. The crack damage was observed to have propagated outwards from the center of the back of the impacted surface, as shown in Figure 12b. From the observation, the crack of the fiber could be observed around the damage area at the back of the impacted surface that had been 
penetrated at $35 \mathrm{~J}$, as shown in Figure 12c. All the tested samples show similar observations, regardless of the gamma radiation dose.

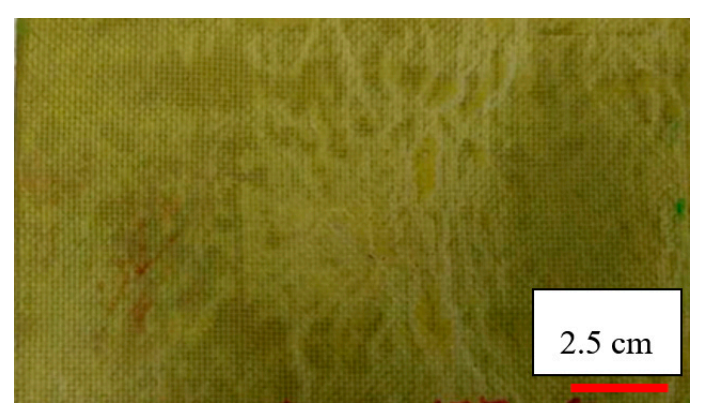

(a)

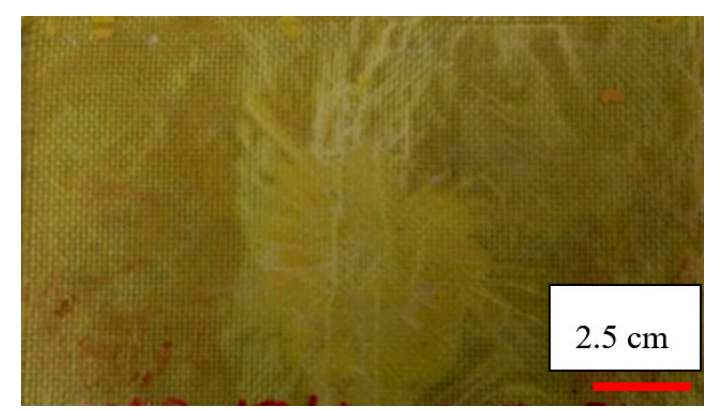

(b)

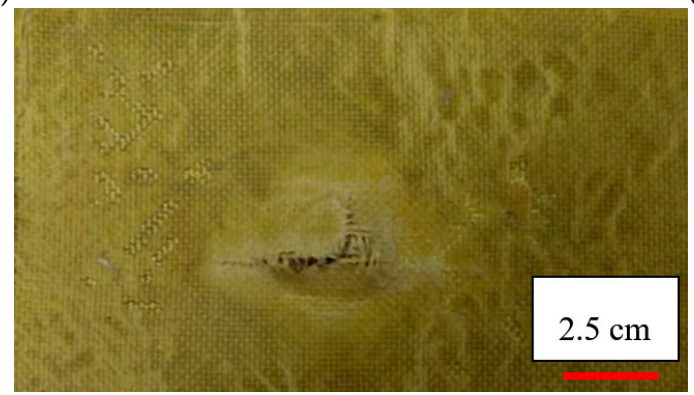

(c)

Figure 12. CAI damage at (a) $10 \mathrm{~J}$, (b) $20 \mathrm{~J}$ and (c) $35 \mathrm{~J}$.

The differences in residual strength with respect to the different composite samples at 25-150 kGy radiation doses were analyzed using ANOVA, and the results are shown in Table 5. The null hypothesis was rejected as the $p$-value of the F-test was less than 0.05 . It was observed that at a $95 \%$ confidence level there is a statistically difference in residual strength among the tested hybrid composites. The normalization line is closer to the data points in the normal probability plot, as shown in Figure 13. This normalization line validates the credibility of the model.

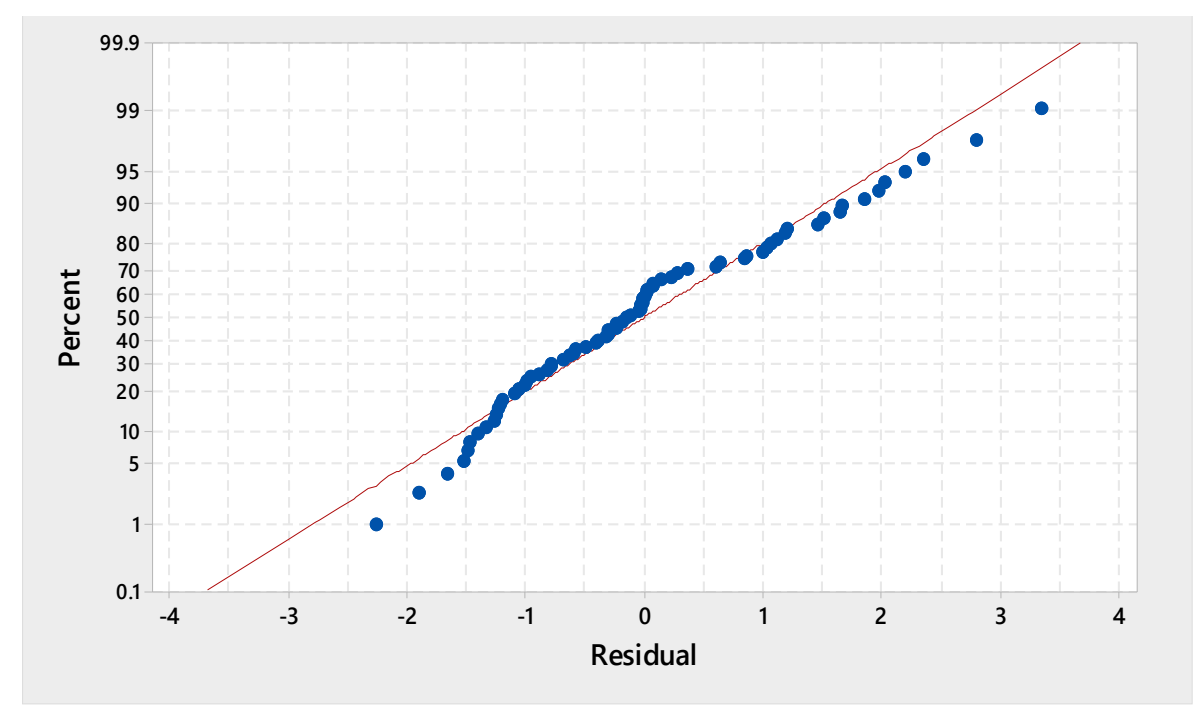

Figure 13. Normal plot for residual strength. 
Table 5. ANOVA results of compressive residual strength.

\begin{tabular}{cccccc}
\hline Source & DF & SS & MS & $f$-Value & $\boldsymbol{p}$-Value \\
\hline Factor & 23 & 2106.3 & 91.580 & 43.68 & 0.000 \\
Error & 48 & 100.6 & 2.097 & NA & NA \\
\hline
\end{tabular}

DF, degrees of freedom; SS, sum of square; MS, mean square.

\section{Conclusions}

This work has investigated the LVI and CAI failure response of Kevlar/OPEFB hybrid composites with/without gamma radiation. Under LVI loadings, Kevlar/OPEFB hybrid composites managed to withstand energy levels from $10 \mathrm{~J}$ to $35 \mathrm{~J}$ without any penetration occurring. However, at $40 \mathrm{~J}$ of energy level, penetration occurred on all gamma irradiated sample. This shows that gamma radiation doses from $25 \mathrm{kGy}$ until $150 \mathrm{kGy}$ did not affect the impact properties of the hybrid composite samples. In general, there is no significant improvement of the impact resistance when the hybrid composites were irradiated with gamma radiation. Under LVI loadings from 10 to $20 \mathrm{~J}$, all samples managed to absorb almost similar amounts of energy after the impact tests. However, at $35 \mathrm{~J}$ of impact energy, the sample irradiated with $50 \mathrm{kGY}$ absorbed the greatest energy compared to the other samples. This shows that samples irradiated with a gamma radiation dose at $50 \mathrm{kGy}$ and above experienced more severe damage compared to other samples. This also shows that to maintain the impact properties performance of the hybrid composites, the optimum gamma radiation dose was less than $50 \mathrm{kGY}$. Under CAI loadings, samples that were impacted with $35 \mathrm{~J}$ of impact energy experienced the most failure modes, including the fiber-matrix breakage and delaminations. This shows that the compressive residual strength of the hybrid composites was dependent on the impact energy tested during the LVI event. From the LVI and CAI results, it can be concluded that Kevlar/OPEFB hybrid composites are suitable for applications that have been exposed to gamma radiation, for example, medical applications and the military industry. However, further and more specific investigation are needed to propose the most suitable application for these hybrid composites.

Author Contributions: Conceptualization, S.M.M.A.; methodology, S.M.M.A. and M.T.H.S.; writing-original draft preparation, S.M.M.A.; writing—review and editing, S.M.M.A., A.U.M.S., and S.N.A.S.; supervision, M.T.H.S., M.J., S.M. and K.A.M.S.; project administration, A.U.M.S. and S.N.A.S.; funding acquisition, M.T.H.S. All authors have read and agreed to the published version of the manuscript.

Funding: This research was funded by Universiti Putra Malaysia (UPM), under Geran Putra Berimpak GPB 9668200.

Acknowledgments: The authors would like to thank the Department of Aerospace Engineering, Faculty of Engineering, Universiti Putra Malaysia and Laboratory of Biocomposite Technology, Institute of Tropical Forestry and Forest Products (INTROP), Universiti Putra Malaysia (HICOE) for the close collaboration in this research.

Conflicts of Interest: The authors declare no conflict of interest.

\section{References}

1. Gururaja, M.; Rao, A.H. A review on recent applications and future propsectus of hybrid composites. Int. J. Soft Comput. Eng. 2012, 1, 352-355.

2. Shubhra, Q.T.; Alam, A. Effect of gamma radiation on the mechanical properties of natural silk fiber and synthetic E-glass fiber reinforced polypropylene composites: A comparative study. Radiat. Phys. Chem. 2011, 80, 1228-1232. [CrossRef]

3. Rubio-Lopez, A.; Artero-Guerrero, J.; Pernas-Sanchez, J.; Santiuste, C. Compression after impact of flax/PLA biodegradable composites. Polym. Test. 2017, 59, 127-135. [CrossRef]

4. Taraghi, I.; Fereidoon, A.; Taheri-Behrooz, F. Low-velocity impact Response woven Kevlar/epoxy laminated composites reinforced with multi-walled carbon nanotubes at ambient and low temperatures. Mater. Des. 2014, 53, 152-158. [CrossRef]

5. Aktas, M.; Karakuzu, R.; Arman, Y. Compression-after impact behaviour of laminated composite plates subjected to low velocity impact in high temperatures. Compos. Struct. 2009, 89, 77-82. [CrossRef] 
6. Bakar, A.A.; Hassan, A. Impact propeties of oil palm empty fruit bunch filled impact modified unplasticised poly (vinyl chloride) composites. J. Teknol. 2003, 39, 73-82.

7. Sivakumar, D.; Kathiravan, S.; Selamat, M.Z.; Said, M.R. A study on impact behaviour of a novel oil palm fibre reinforced metal laminate system. Arpn J. Eng. Appl. Sci. 2016, 11, 2483-2488.

8. Channabasavaraju, S.; Shivanand, H.; Kumar, S.S. Investigation of low velocity impact properties of Kevlar fiber reinforced polymer matrix composites. Int. J. Eng. Res. Technol. 2013, 2, 680-682.

9. Ying, S.; Mengyun, T.; Zhijun, R.; Baohui, S.; Li, C. An experiemental investigation on the low-velocity impact response of carbon-aramid/epoxy hybrid composite laminates. J. Reinf. Plast. Compos. 2017, 36, 422-434. [CrossRef]

10. Gustin, J.; Joneson, A.; Mahinfalah, M.; Stone, J. Low velocity impact of combination Kevlar/carbon fiber sandwich composites. Compos. Struct. 2005, 69, 396-406. [CrossRef]

11. Shaari, N.; Jumahat, A.; Razif, M. Impact resistance properties of Kevlar/glass fibrt hybrid composite laminates. J. Teknol. 2015, 76, 93-99.

12. Imielinska, K.; Guillaumat, L. The effect of water immersion ageing on low-velocity impact behaviour of woven aramid-glass fibre/epoxy composites. Compos. Sci. Technol. 2004, 64, 2271-2278. [CrossRef]

13. Ismail, F.; Sultan, M.T.; Hamdan, A.; Shah, A.U.M. A study on the low velocity impact response of hybrid kenaf-Kevlar composite laminates through drop test rig technique. Bioresources 2018, 13, 3045-3060. [CrossRef]

14. Martins, A.; Aboura, Z.; Harizi, W.; Laksimi, A.; Khellil, K. Analysis of the impact and compression after impact behaviour of tufted laminated composites. Compos. Struct. 2018, 184, 352-361. [CrossRef]

15. Khalil, H.A.; Jawaid, M.; Bakar, A.A. Woven hybrid composites: Water absorption and thickness swelling behaviours. BioResources 2011, 6, 1043-1052.

16. Ali, A.; Shaker, Z.R.; Khalina, A.; Sapuan, S.M. Development of Anti-Ballistic Board from Ramie Fiber. Polym. Plast. Technol. Eng. 2011, 50, 622-634. [CrossRef]

17. ASTM D7137/D7137M-17, Standard Test Method for Compressive Residual Strength Properties of Damaged Polymer Matrix Composite Plates; ASTM International: West Conshohocken, PA, USA, 2017.

18. Reis, P.; Ferreira, J.; Santos, P.; Richardson, M.; Santos, J. Impact response of Kevlar composites with filled epoxy matrix. Compos. Struct. 2012, 94, 3520-3528. [CrossRef]

19. Yahaya, R.; Sapuan, S.M.; Jawaid, M.; Leman, Z.; Zainudin, E.S. Investigating Ballistic Impact Properties of Woven Kenaf-aramid Hybrod Composites. Fibers Polym. 2016, 17, 275-281. [CrossRef]

20. Silva, A.O.D.; Monsores, K.G.d.C.; Oliveira, S.d.S.A.; Weber, R.P.; Monteiro, S.N. Ballistic behavior of a hybrid composite reinforced with curaua and aramid fabric subjected to ultraviolet radiation. J. Mater. Res. Technol. 2018, 7, 584-591. [CrossRef]

21. Feraboli, P.J.; Ireland, D.R.; Kedward, K.T. The Role of Force and Energy in Low Velocity Impact Events. In Proceedings of the 45th AIAA/ASCE/AHS/ASC Structures, Structural Dynamics \& Material Conference, Palm Springs, CA, USA, 19-22 April 2004.

22. Kessler, A.; Bledzki, A.K. Low Velocity Impact Behavior of Glass/Epoxy Cross-Ply Laminates with Different Fiber Treatments. Polym. Compos. 1999, 2, 269-278. [CrossRef]

23. Unnikrishnan, K.P.; Thachil, E.T. Toughening of epoxy resins. Des. Monomers Polym. 2006, 9, $129-152$. [CrossRef]

(C) 2020 by the authors. Licensee MDPI, Basel, Switzerland. This article is an open access article distributed under the terms and conditions of the Creative Commons Attribution (CC BY) license (http://creativecommons.org/licenses/by/4.0/). 